\title{
Techno-Economic Viability of Large Scale Solar Integration with Battery Storage for Grid Substations: A Case Study for Sri Lanka
}

\author{
L.G.H.M. Prabhani, J.V.U.P. Jayatunga and J.R. Lucas
}

\begin{abstract}
Over the past few years, utility scale Solar PV Power plants (SPVPs) are being added to the national grid at Medium Voltage (MV) distribution networks. However, the performance of the distribution networks can adversely be affected, if they are connected without the knowledge of optimum sizes and locations. Challenge in utilization of electricity generated from the weather dependent SPVPs is in its intermittency and non-dispatchability, rendering it hard to match supply and demand which themselves are variable. The difficulties associated with proliferation of SPVPs could be alleviated by the proper use of Battery Energy Storage Systems (BESSs). The impact of installing BESS on the quality of distribution networks during the sizing of battery storage has been considered in this research.
\end{abstract}

In this paper, the optimal placement of SPVPs and B-SPVPs in terms of size and location is evaluated for minimisation of energy loss bounded by voltage constraints preserving the power balance. The required optimization is carried out using Mixed Integer Programming with Genetic Algorithm (MIGA) and Particle Swarm Optimization (PSO) techniques. The proposed approach was utilised to study the techno economic viability of integration of solar Photovoltaic (PV) and battery energy storage systems to a $33 \mathrm{kV}$ practical network in Sri Lanka - Tissa 1 feeder in Hambantota Grid Substation (GSS). A financial evaluation was carried out to inspect the viability of SPVP and B-SPVP in Tissa 1 feeder using the optimized results.

Keywords: Backward-Forward Sweep Load flow, Large scale solar power plants, Battery storage connected large scale solar power plants, Mixed Integer Programming with Genetic Algorithm, Particle Swarm Optimization

\section{Introduction}

Recently, the electricity demand in Sri Lanka has been increasing drastically while the conventional energy sources are being depleted resulting in inadequate supply. Exploitation of power from sustainable power sources has been expanded due to their money-saving features and eco-friendliness. Together with the global push and Sri Lankan government's goal of achieving 100\% renewable energy (RE) share by the year 2050, various programmes like Battle for Solar and connection of 1MW solar power plants in 150 different locations in identified Grid Substations (GSSs) were launched.

The addition of Renewable Energy Sources (RESs) at the distribution network is controlled by capacity limitations, produced as outcomes of stability studies performed by Generation and Transmission Planning Unit of Ceylon Electricity Board (CEB). These studies include the addition of Renewable Energy (RE) with the proposals for possible GSSs and forecasts based on capital and operational costs, while considering intermittency and uncertainty of RESs at the same time.
The present practice is to determine the allowable RE share of the generation mix and allocate fractions of it to GSSs, considering simulations for power system for stability, causing a barrier for grid autonomy concept. Moreover, at present, Sri Lankan power system is not robust enough to accept intermittency of RES based power generation as the frequency controlling is mainly done by hydro power plants rather than fast responsive gas turbine based power plants. On the other hand, distribution divisional Planning \& Development branches propose to have distributed generators as alternatives to curb

Eng. (Mrs.) L.G.H.M. Prabhani, AMIE(SL), Electrical Engineer (Ceylon Electricity Board), BScEng (Moratuwa), Sc(Moratuwa).

Email:mekhala.prabhani@gmail.com

ORCID ID: $h$ ttp://orcid.org/0000-0002-4846-4408

Dr. J.V.U.P. Jayatunga, CEng, MIE(SL),

Senior Lecturer Grade I, BSc Eng(Moratuwa), MSc(Moratuwa),

$\mathrm{PhD}$ (Wollongong),

Email:upuli@uom.lk

ORCID ID: $h$ ttp://orcid.org/0000-0001-5245-749X

Prof. J.R. Lucas, Int. PEng., CEng, FIE(SL), Emeritus Professor BSc Eng(Cey), MSc(Manch), PhD(Manch), FIEE, MCS(SLanka) ORCID ID: $h$ ttp://orcid.org/0000-0001-7215-0815 
the power system losses. Lengthy feeders and feeders that are unable to upgrade with higher current capacity conductors result in setting barriers to the local community's development. Thus CEB power system planners are eagerly searching for solutions to enhance distribution network performance and to maximize utilization of Distributed Generator (DG) resources at the same time.

\subsection{Optimal DG Placements}

Penetration of Distributed Energy Resources (DERs) is overturning the traditional unidirectional power flow concept while giving prime concern to technical \& economic aspects. DGs have advantages like enhanced efficiency and reliability in terms of peak power reduction and increased power quality, while giving prime high ground to energy loss and voltage stability [1]. Many developed countries have been encouraging proliferation of DGs in their power network at distribution level, anticipating grid autonomy.

Combination of Battery Energy Storage Systems (BESS) with solar Photovoltaic (PV) systems which are intermittent in nature provide an opportunity to dispatch PV plants the same way as traditional thermal power plants. This has offered flexibility in connecting renewable power safely and securely, while storing surplus energy [2]. In many cases, this integration of PV systems and BESS has been done by charging BESS entirely from PV plant output and discharging the stored energy during non-solar generating times. The BESS output has used to supply the demand while excess energy is either sold to the electrical grid or time shift by storing in the battery to discharge later [3].

Having identified the trend in co-locating PV plants with BESS due to extensive benefits offered, researchers have studied how the proliferation of utility scale SPVPs and BESSs can be optimized subjected to many objectives. These approaches include analytical methods, numerical methods and heuristic algorithms. Heuristic methods are generally considered robust and provide optimal solutions for large and complex problems [4,5]. Among them, Genetic Algorithm (GA) and Particle Swarm Optimization (PSO) are frequently used. The most common objectives for these kind of optimization problems include minimization of cost associated with net power purchase from the electric grid and battery storage or reduction in peak electricity purchase from the grid while meeting the load, simultaneously $[6,7]$.
In previous studies $[1,8,9,10]$, SPVPs' and BSPVPs' sizes have been predetermined and non-generalized whereas the real requirement is to find the optimal size of B-SPVP in any given location. The main benefits of integrating DGs to distribution networks include the reduction in power losses and improvements in Bus voltage profiles. However, technically most important is that no study had been conducted in integration of large scale SPVPs with and without BESS in Sri Lanka, primarily owing to prevailing prohibitively high cost of BESS.

\subsection{Optimal SPVP Placements in Sri Lankan Context}

As far as the current Sri Lankan energy mix is considered, Sri Lanka has reaped the fullest economical potential of major RES in terms of large hydro while other RESs as mini hydro, solar and wind will be predominant in forthcoming years as it will exceed the major hydro capacity by 2023 [12].

Even though there is abundance of solar energy, Sri Lanka is not in a financially stable position to afford BESS technologies in the near future. As BESS price makes up a large portion of a BESS installing project cost, still Sri Lanka has not considered utility scale BESS as a viable option in long term generation plans prepared by the CEB owing to alarmingly high cost of BESS (capital cost per unit of B-SPVP is approx. 2000 USD/kWh [13]).

BESS unit price is forecast to reach a value that is commercially viable by the year 2025 [14]. Thus, the viability check studies to assess the integration of large scale SPVP and B-SPVP concepts in distribution level will ease the burden on power system planners and keep Sri Lanka ready to welcome BESS technologies into these SPVP and B-SPVP concepts.

The paper presents the determination of optimum size and location for a large scale SPVP that can make a GSS self-sufficient, subjected to voltage and energy loss constraints with and without battery storage. Section 2 presents the development of a solar PV power output model. Theory and mathematical formulation related to the research is detailed under Section 3. The results obtained by applying the developed model to a practical MV feeder (Tissa 1 feeder of Hambantota GSS) are presented in Section 4 . Section 5 presents a financial evaluation carried out to determine financial viability of SPVP and B-SPVP while Section 6 summarizes the conclusions. 


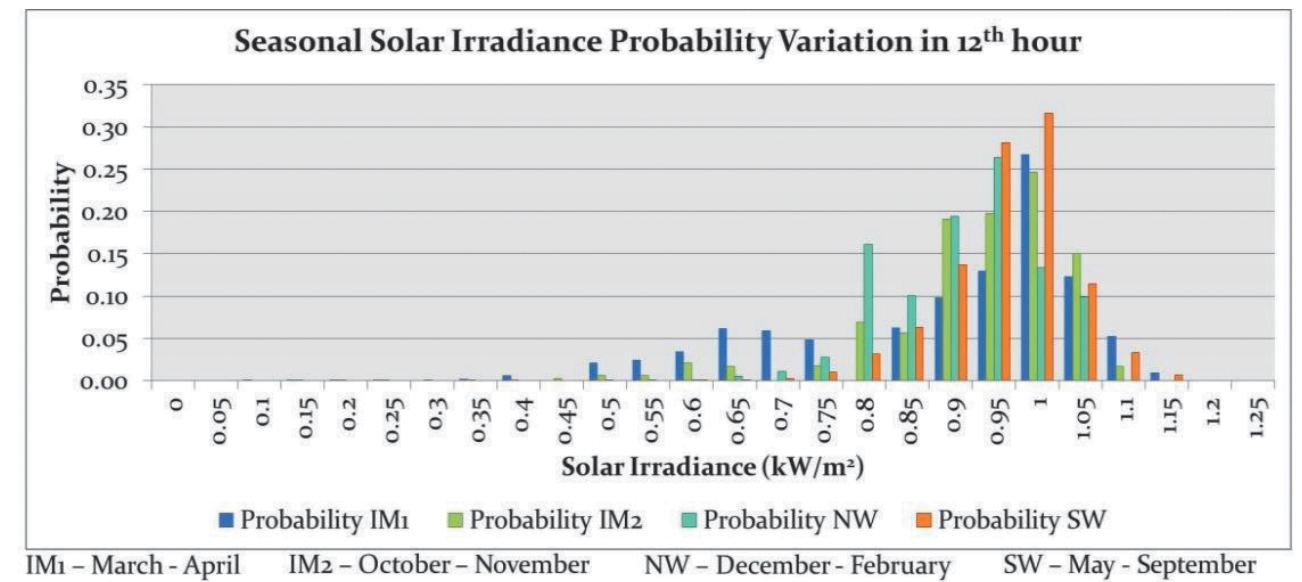

Figure 1 - Seasonal Solar Irradiance Probability Variation for $12^{\text {th }}$ hour in Hambanthota

\section{Modelling of Solar PV Power Output}

\subsection{Development of Solar PV Module Power Output Model}

Meteorological data for SPVP output modelling was taken from the weather station located at Saga Solon Solar Power Park in Hambantota. The output from a solar PV module was modelled using Beta probability density function (PDF) to generate 24 hour solar irradiance curve as in [15] using MATLAB.

In this approach, intermittency of solar resource was captured as it is essential in SPVP or B-SPVP planning. To investigate whether there is any seasonality effect of solar irradiance, the collected weather data was partitioned into 4 seasons as depicted in [16] depending on the rainy seasons of Sri Lanka as North-East (NWDecember to February), South-West (SW-May to September), and the two inter-monsoonal periods. The first inter-monsoonal period $\left(\mathrm{IM}_{1}\right)$ is from March to April and the second inter- with the aid of characteristic values [17] as given in Table 1.

Table 1 - Characteristics of PV Module

\begin{tabular}{|l|l|}
\hline$I_{S C}$ (Short circuit current in $\left.\mathrm{A}\right)$ & 45 \\
\hline $\mathrm{OCC}_{\text {OC }}($ Open circuit voltage in $\mathrm{V})$ & 6.85 \\
\hline $\mathrm{IMPP}($ Current at maximum power point in $\mathrm{A})$ & 34.45 \\
\hline $\mathrm{VMPP}$ (Voltage at maximum power point in $\mathrm{V})$ & 7.18 \\
\hline $\begin{array}{l}\text { NOCT (Nominal operating temperature of cell in } \\
\left.{ }^{0} \mathrm{C}\right)\end{array}$ & 42.32 \\
\hline $\mathrm{KV}$ (Voltage temperature coefficient in $\left.\mathrm{V} /{ }^{\circ} \mathrm{C}\right)$ & 0.058 \\
\hline $\mathrm{Ki}$ (Current temperature coefficient in $\left.\mathrm{A} /{ }^{\circ} \mathrm{C}\right)$ & -0.33 \\
\hline
\end{tabular}

Overall efficiency of the solar PV plant was assumed as $95 \%$ and the inverter power factor was considered as unity.

\section{$2.2 \quad$ Variation of Solar Irradiance}

As appeared in Figure 1, the solar irradiance of $1 \mathrm{~kW} / \mathrm{m}^{2}$ is the frequent solar irradiance that Hambantota receives based on the weather data collected and it occurs in the SW monsoon period. During this period, a marked increase in solar radiation is shown as an effect of the central highland acting as an orographic barrier

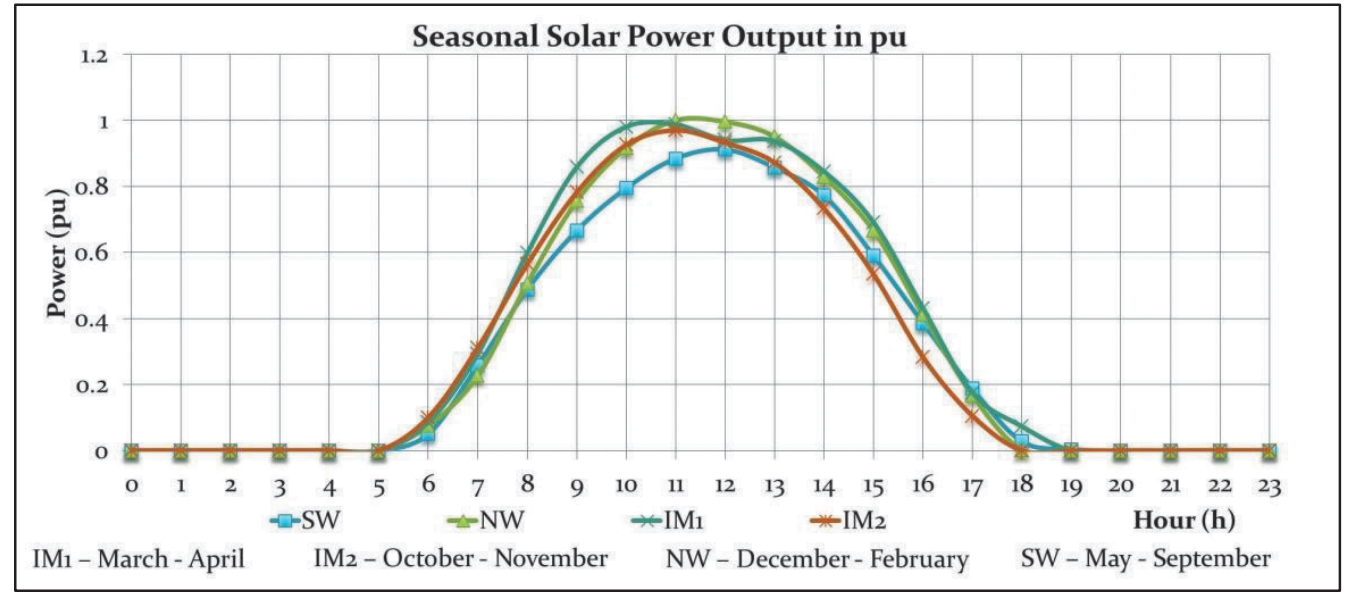

Figure 2 - Solar PV Module Seasonal Power Output

monsoonal period $\left(\mathrm{IM}_{2}\right)$ is from October to November. Solar PV power output is modelled to South-West monsoonal blowing, making it a dry desiccating wind when reaching the dry region. Therefore this value is extensively site- 
specific. Figure 2 presents the seasonality effect on solar module power output based on the collected weather data, for the four weather seasons concerned. Insignificant variation was observed on the output from solar PV module in per unit (pu) between the four seasons. Thus, a model with constant power output is considered, assuming there is no seasonality effect on the PV output.

\section{Optimal Solar Integration with Battery Storage Based on Energy Loss Minimization}

\subsection{Self-sufficiency Level in terms of Energy Penetration}

The technical viability of integrating SPVPs and B-SPVPs can be evaluated in terms of Total Energy Loss Index (TELI) given in equation (1) while objective being the minimization of TELI over a day subjected to the following constraints.

$$
T E L I=\frac{P^{D G} \text { loss_Total_Day }_{\text {Poss_Total__ay })}}{P_{\text {lon }}}
$$

1. SPVP Capacity

The SPVP capacity depends on the distribution network.

\section{BESS Capacity}

$$
0<\text { BESS Capacity } \leq x \times \text { SPVP Capacity }
$$

The BESS capacity depends on the distribution network.

3. Hourly Optimum Energy (OE) Levels

$$
0<O E \leq 100 \% \times \text { Hourly Total Load }
$$

It was identified that there exists an hourly $\mathrm{OE}$ beyond which total energy loss is increased again as the solar energy penetration advances. OE of each hour was determined by varying the distributed resource size expressed as a percentage of hourly total load while keeping the bus to be connected as the same as the optimized location resulted from optimization of SPVP.

4. Load Level (LL) to charge/discharge BESS

$$
0<L L \leq 100 \% \times \text { Peak Load }
$$

5. Network Power Balance

$P_{G S S}(t)+P^{D G}(t)=P^{D}{ }_{\text {Total }}(t)+P_{\text {loss }_{\text {Total }}}(t)(2)$

$Q_{G S S}(t)+Q^{D G}(t)=Q^{D}{ }_{\text {Total }}(t)+Q_{\text {loss }_{\text {Total }}}(t)(3)$

$P_{G S S}(t) \& Q_{G S S}(t)$ are active and reactive power supplies from GSS to the distribution network during time $(\mathrm{t})$, respectively.
6. SPVP or B-SPVP Placement (Connected Bus)

$2 \leq D G_{\text {Connected Bus }} \leq$ Max. of number of buses

Bus no. 1 is considered as the 'Slack Bus'.

7. Bus Voltage Limits

$V_{\min }(=0.95) \leq$ Bus Voltage $\leq V_{\max }(=1.0)$

The Backward-Forward Sweep Flow (BFSF) load flow is performed to find the bus voltages and power losses across the branches.

For the determination of self-sufficiency level in terms of energy penetration under each case, it is evaluated as a percentage of the ratio between energy delivered after installing SPVP or B-SPVP to the energy delivered when there is neither SPVP nor B-SPVP is connected, as shown in the equation (4).

Self-sufficiency level in terms of energy penetration= $\frac{\sum_{t=1}^{24} P^{D G}}{\left.\sum_{t=1}^{24} P_{D}\right)} \times 100 \%$

$P D G$ is the hourly active power delivered when SPVP or B-SPVP connected to the distribution network whereas $P_{D}$ being the hourly active power delivered when neither SPVP nor BSPVP is connected to the distribution network.

\subsection{Power Loss across Branches}

Equations for power loss of $i^{\text {th }}$ branch that lies between $k^{\text {th }}$ and $k+1^{\text {th }}$ nodes during $t^{\text {th }}$ hour are described with the following notations.

- $P_{D, k+1}-$ Active power demand of $k+1^{\text {th }}$ node

- $Q_{D, k+1}$-Reactive power demand of $k+1^{\text {th }}$ node

- $P^{S P V P}(t), k+1$ - Active power demand during $t^{\text {th }}$ hour when connected to $k+1^{\text {th }}$ node at Case 2

- $Q^{S P V P}(t), k+1-\quad$ Reactive power demand during $t^{\text {th }}$ hour when connected to $k+1^{\text {th }}$ node at Case 2

- $\operatorname{PB-SPVP}(t), k+1$ - Active power demand during $t^{\text {th }}$ hour when connected to $k+1^{\text {th }}$ node at Case 3

- $Q^{B-S P V P}(t), k+1-$ Reactive power demand during $t^{\text {th }}$ hour when connected to $k+1^{\text {th }}$ node at Case 3

3.2.1 Case 1: Power loss when there is no SPVP connected to the network

1. Active power loss across $\mathrm{i}^{\text {th }}$ branch; $P_{\text {loss }(i)}$

$$
P_{\text {loss }(i)}=R_{(i)} \times \frac{P_{D, k+1}{ }^{2}+Q_{D, k+1}{ }^{2}}{\left|V_{k+1}\right|^{2}}
$$


2. Reactive power loss across $i^{\text {th }}$ branch; $Q_{\text {loss }(i)}$

$$
Q_{\text {loss }(i)}=X_{(i)} \times \frac{P_{k+1}{ }^{2}+Q_{k+1}{ }^{2}}{\left|V_{k+1}\right|^{2}}
$$

3. Total power loss during a day; $P_{\text {loss_total__ay }}$

$P_{\text {loss_Total_Day }}=\sum_{i=1}^{\text {No.of branches }} P_{\text {loss }(i)}+j Q_{\text {loss }(i)}(7)$

3.2.2 Case 2: Power loss when only a SPVP is connected to $k+1^{\text {th }}$ node of the network

1. Active power during $t^{\text {th }}$ hour; $P_{(i)}(t)$

$$
P_{(i)}(t)=P_{D(k+1)}(t)-P_{(k+1)}^{S P V}(t)+P_{\text {loss }(i)}(t)
$$

2. Reactive power during $t^{\text {th }}$ hour; $Q_{(i)}(t)$

$$
\begin{aligned}
Q_{(i)}(t)= & Q_{D(k+1)}(t)-Q^{S P V}{ }_{(k+1)}(t)+ \\
& Q_{\text {loss }(i)}(t) \ldots(9)
\end{aligned}
$$

$Q^{S P V P}(k+1)(t)$ is zero as the inverter is assumed to be unity power factor.

3. Active power loss across $i^{\text {th }}$ branch; $\frac{P S P V P_{\text {loss }(i)}}{P^{S P V} \text { loss }(i)}=R_{(i)}$

$\times \frac{\left(P_{D, k+1}-P_{(k+1)}^{S P V}\right)^{2}+\left(Q_{D, k+1}-Q_{(k+1)}^{S P V}\right)^{2}}{\left|V_{k+1}\right|^{2}}$

4. Reactive power loss across $i^{\text {th }}$ branch; $\bar{Q}^{\operatorname{SPVP}_{\text {loss }(i)}}$

$Q^{S P V}{ }_{\text {loss }(i)}=X_{(i)}$

$\times \frac{\left(P_{D, k+1}-P^{S P V}{ }_{(k+1)}\right)^{2}+\left(Q_{D, k+1}-Q_{(k+1)}^{S P V}\right)^{2}}{\left|V_{k+1}\right|^{2}}$.

5. Total power loss during a day; $\underline{P S P V P}_{\text {loss_Total_Day }}$

$$
\begin{aligned}
P^{S P V}{ }_{\text {loss_Total_Day }} & =\sum_{i=1}^{\text {no. of branches }} P^{S P V}{ }_{\text {loss }(i)} \\
& +j Q^{S P V}{ }_{\text {loss }(i)}
\end{aligned}
$$

3.2.3Case 3: Power loss when battery connected large scale solar power plant is connected to the network
1. Active power during $t^{\text {th }}$ hour; $P_{(i)}(t)$

$$
\begin{aligned}
P_{(i)}(t)= & P_{D(k+1)}(t)-P^{B-S P V}{ }_{(k+1)}(t)+ \\
& P_{\text {loss }(i)}(t) \ldots . . .(13)
\end{aligned}
$$

2. Reactive power during $t^{\text {th }}$ hour; $Q_{(i)}(t)$

$$
\begin{gathered}
Q_{(i)}(t)=Q_{D(k+1)}(t)-Q^{B-S P V}{ }_{(k+1)}(t)+ \\
Q_{\text {loss }(i)}(t) \ldots . .(14)
\end{gathered}
$$

Since the inverter is assumed to be unity power factor, $Q^{B-S P V P}(k+1)(t)$ is zero.

3. Active power loss across $i^{\text {th }}$ branch; $P^{B-}$ $\stackrel{S P V P}{l o s s(i)}_{\text {L }}$

$$
\begin{aligned}
& P^{B-S P V}{ }_{\operatorname{loss}(i)}=R_{(i)} \times \\
& \frac{\left(P_{D, k+1}-P^{B-S P V}{ }_{(k+1)}\right)^{2}+\left(Q_{D, k+1}-Q^{B-S P V}{ }_{(k+1)}\right)^{2}}{\left|V_{k+1}\right|^{2}} \ldots .
\end{aligned}
$$

4. Reactive power loss across $i^{\text {th }}$ branch; $Q^{B-}$ $\stackrel{S P V P}{l o s s}(i)_{\text {L }}$

$$
Q^{B-S P V}{ }_{\operatorname{loss}(i)}=X_{(i)}
$$

$\times \frac{\left(P_{D, k+1}-P_{(k+1)}^{B-S P V}\right)^{2}+\left(Q_{D, k+1}-Q_{(k+1)}^{B-S P V}\right)^{2}}{\left|V_{k+1}\right|^{2}}$ .....(16)

5. Total power loss during a day; $P^{B-}$ $\stackrel{S P V P}{\text { loss_Total_Day }}_{\text {Da }}$

$$
\begin{aligned}
& P^{B-S P V} \text { loss_Total_Day } \\
& =\sum_{i=1}^{\text {no. of branches }} P^{B-S P V} \operatorname{loss}(i) \\
& +j Q^{B-S P V} \operatorname{loss}(i)^{\cdots}
\end{aligned}
$$

\subsection{4-h Load Profile}

To address hourly variability of load over a day, a 24-hour load profile is incorporated during modelling in MATLAB. The hourly active and reactive power variation of the connected loads on an average day for Hambantota GSS is as shown in Figure 3, based on [18].

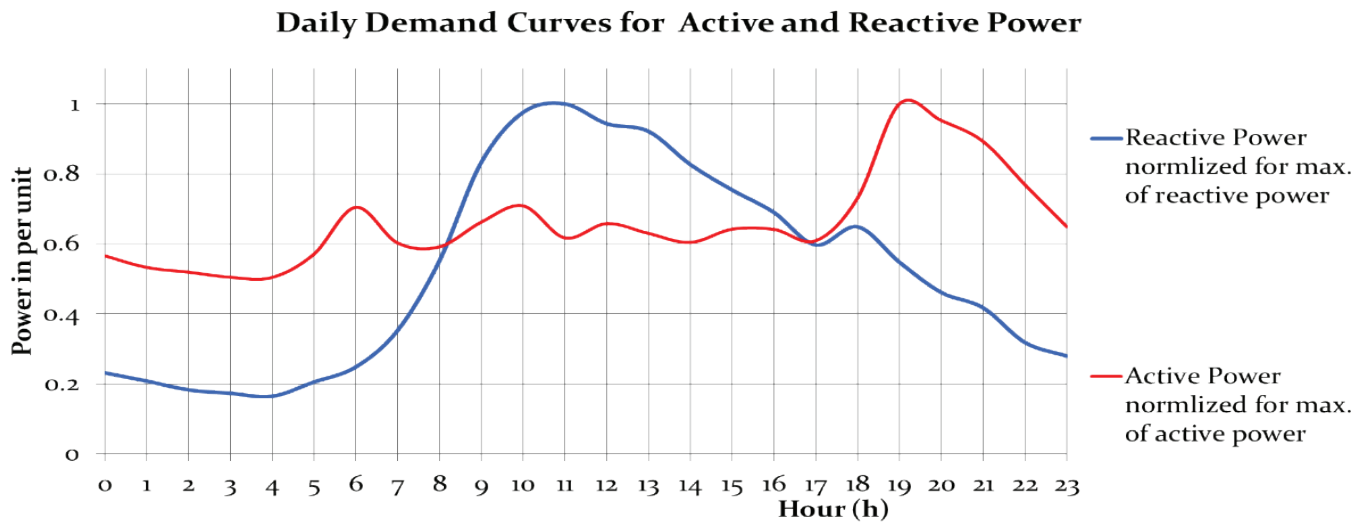

Figure 3 - Daily Demand Curves for Active and Reactive Power 
The developed model was applied for a practical MV network connected to Hambantota GSS. Hambantota GSS resides where ample and high tense solar irradiance is available. Besides modelling the whole GSS, Tissa 1 feeder with bus numbers (which is given in Figure 4) was analyzed and interpreted, as the distribution feeders of a GSS can be represented as one feeder connected to GSS.

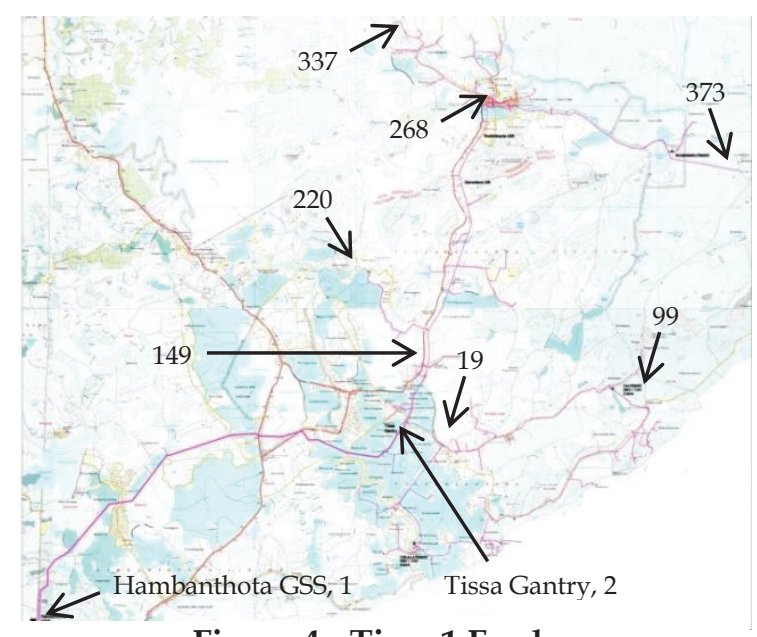

Figure 4 - Tissa 1 Feeder

\subsection{BESS Control Logic}

For B-SPVP connected case, BESS control logic provided in Figure 5 was used to utilize power from the B-SPVP to cater for the total hourly demand of the network, drawing minimum amount of power from the main grid whenever possible. The BESS was charged from the output from SPVP. The floor and ceiling levels, either to charge or discharge batteries, are decided by defining two parameters, LL and $\mathrm{OE}$, respectively. Both the charge and discharge efficiencies are assumed to be $95 \%$.

\section{Application of Loss Minimization Based Optimization to Tissa 1 Feeder}

\subsection{Basic Power Flow Results}

The basic power flow results resulted from Backward-Forward Sweep Load Flow MATLAB model developed for Tissa 1 feeder of $167.69 \mathrm{~km}$, assuming the feeder is balanced, is as shown in Table 2.
Table 2 - Basic Power Flow Results Without Concerning Hourly Load Variation for Tissa 1 Feeder

\begin{tabular}{|l|l|}
\hline $\begin{array}{l}\text { Total connected } \\
\text { load }\end{array}$ & $\begin{array}{l}:: \text { Active power - 6.598MW } \\
\text { : Reactive power - 2.33Mvar }\end{array}$ \\
\hline Maximum voltage & $: 1 \mathrm{pu}$ \\
\hline Minimum voltage & $: 0.899 \mathrm{pu} @$ Bus no. 373 \\
\hline $\begin{array}{l}\text { Total real energy } \\
\text { loss }\end{array}$ & $: 462 \mathrm{kWh}$ \\
\hline
\end{tabular}

\subsection{Optimization Results -SPVP Connected} Scenario

The TELI values using MIGA and verified by PSO models resulted as 0.686 . The best bus to connect the SPVP and the optimum capacity of SPVP resulted as $149^{\text {th }}$ bus and $14.057 \mathrm{MW}$, respectively. Network energy balance over a day has been preserved for the cases before and after connecting the SPVP to Tissa 1 feeder as evident from Table 3.

In Table 3, E_DG, E_DGLoss, E_LT, E_SubSol, E_SubInitial are energy output of the SPVP, energy loss of the SPVP, energy requirement of the connected loads, energy requirement of the GSS and energy requirement of GSS before connecting SPVP, respectively.

Table 3 - Network Energy Balance Preservation Check Before \&After Optimum SPVP Connected Cases

\begin{tabular}{|c|c|c|c|c|}
\hline \multicolumn{3}{|l|}{ E_DG } & \multicolumn{2}{|c|}{$42,048.9 \mathrm{kWh}$} \\
\hline \multicolumn{3}{|c|}{ E_DGLoss } & \multicolumn{2}{|l|}{ 3,195.8Wh } \\
\hline \multicolumn{3}{|l|}{ E_LT } & \multicolumn{2}{|c|}{$104,513.7 \mathrm{kWh}$} \\
\hline \multicolumn{3}{|c|}{ Initial Total energy loss } & \multicolumn{2}{|c|}{$4,658.3 \mathrm{kWh}$} \\
\hline \multicolumn{3}{|c|}{$\begin{array}{l}\text { E_SubSol=E_LT- } \\
\text { E_DG+E_DGLoss }\end{array}$} & \multicolumn{2}{|c|}{$65,660.6 \mathrm{kWh}$} \\
\hline \multicolumn{3}{|c|}{$\begin{array}{l}\text { E_SubInitial=E_LT+Initial } \\
\text { Total energy loss }\end{array}$} & \multicolumn{2}{|c|}{$109,172 \mathrm{kWh}$} \\
\hline \multicolumn{5}{|c|}{$E_{\text {Substation }}(t)+E_{D G}(t)=E_{L T}(t)+E_{\text {Loss-Total }}(t)$} \\
\hline Case & E-SubSol & E-DG & E-Load & E-Loss \\
\hline Initial & 109,172 & 0 & $104,513.7$ & $4,658.3$ \\
\hline SPVP & $65,660.6$ & $42,048.9$ & $104,513.7$ & $3,195.8$ \\
\hline
\end{tabular}

In order to minimize total energy loss over a day for Tissa 1 feeder, it is required to install a SPVP of 14.057 MW capacity at the Bus No. 149. It would result in a $31.4 \%$ reduction of energy loss and the lowest bus voltage is improved to $0.963 \mathrm{pu}$ from $0.899 \mathrm{pu}$ at the Bus no. 373. The self-sufficiency level of the Tissa 1 feeder is $40.23 \%$. This means, with the installation of a large scale SPVP of $14.057 \mathrm{MW}$ at the $149^{\text {th }}$ bus, the feeder is capable of catering $40.23 \%$ of its total energy requirement itself. Hourly variation of power from main grid and SPVP with time are depicted in Figure 6. Excess energy transition from SPVP to main grid during $10^{\text {th }}, 11^{\text {th }}, 12^{\text {th }}, 13^{\text {th }}$ and $14^{\text {th }}$ hours is also indicated in Figure 6. 


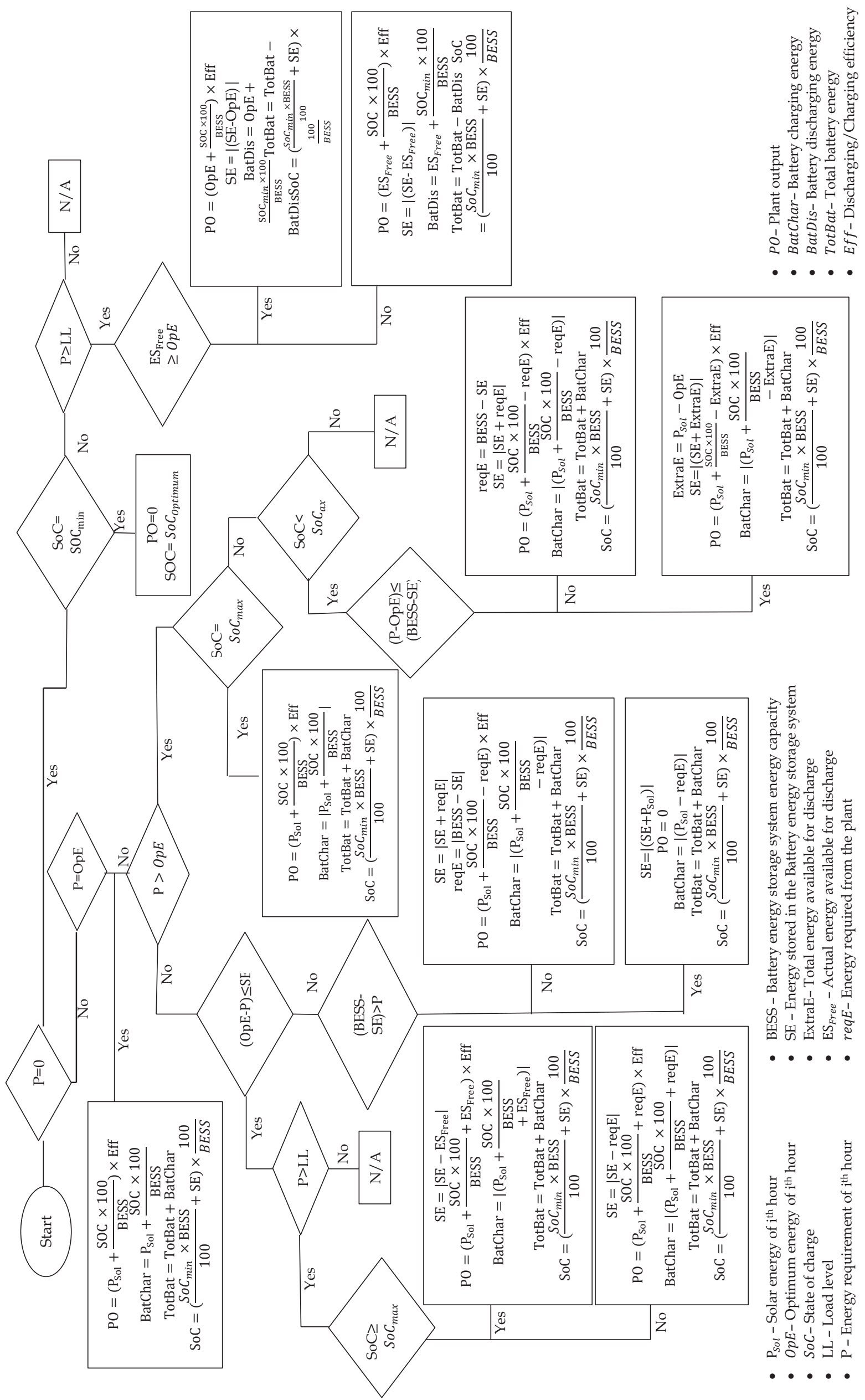

Figure 5 - BESS Control logic for $i^{\text {th }}$ hour 


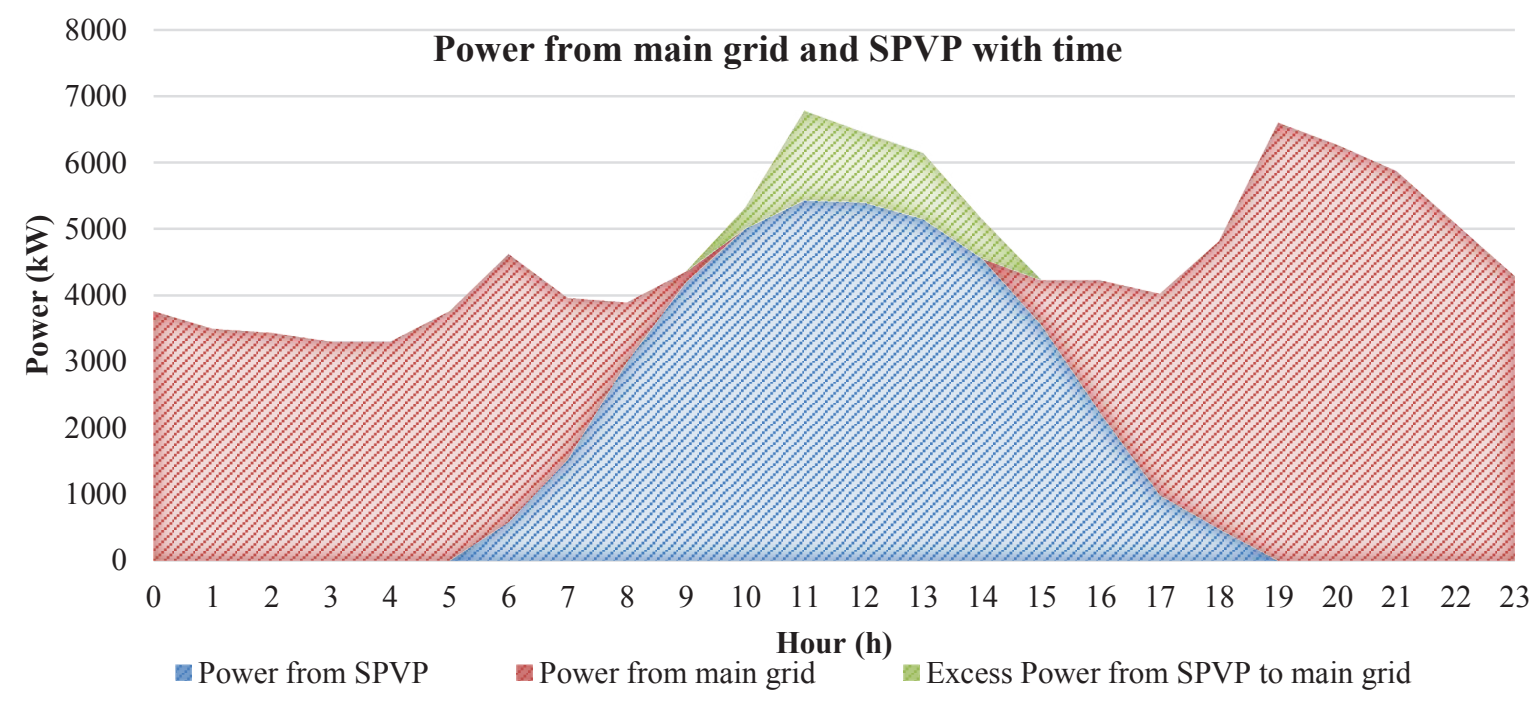

Figure 6 - Power from Main Grid and SPVP with Time

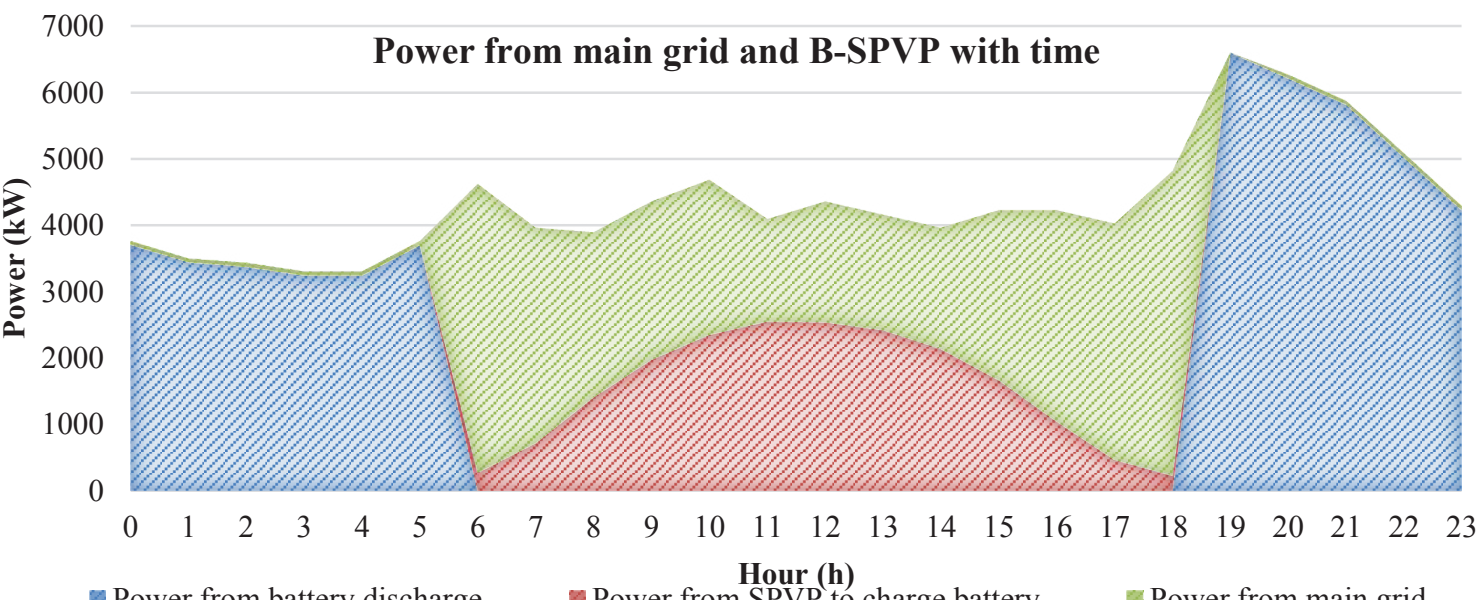

Figure 7 - Power from Main Grid and B-SPVP with Time

\subsection{Optimization Results - B-SPVP Connected Scenario}

The TELI values using MIGA and verified by PSO models resulted as 0.2887 . The best bus to connect the B-SPVP and the optimum capacity of B-SPVP are 149 and $6.598 \mathrm{MW}$, respectively. Table 4 depicts how preservation of power balances is maintained before and after connecting the B-SPVP to the Tissa 1 feeder. In Table 4, E_DG, E_DGLoss, E_LT, E_SubSol \& Bat, E_SubInitial are energy output of the BSPVP, energy loss of the B-SPVP, energy requirement of the connected loads, energy requirement of the GSS and energy requirement of GSS before connecting B-SPVP, respectively.

To minimize total energy loss over a day for Tissa 1 feeder, it is required to install a B-SPVP comprising a SPVP with $6.598 \mathrm{MW}$ and a BESS of $14.663 \mathrm{MWh}$ at the Bus No. 149. This would result in a $71.13 \%$ reduction of energy loss, a greater reduction of energy loss existed for optimized SPVP connected case. The size of SPVP in optimized B-SPVP has now decreased to 6.598 MW from its capacity of 14.06 MW for optimizing only SPVP.

Table 4 - Network Energy Balance Preservation Check Before \& After Optimum B-SPVP Connected Cases

\begin{tabular}{|c|c|c|c|c|}
\hline \multicolumn{3}{|l|}{ E_DG } & \multicolumn{2}{|c|}{$64,892.5 \mathrm{kWh}$} \\
\hline \multicolumn{3}{|c|}{ E_DGLoss } & \multicolumn{2}{|c|}{$1,344.77 \mathrm{kWh}$} \\
\hline \multicolumn{3}{|l|}{ E_LT } & \multicolumn{2}{|c|}{$104,513.7 \mathrm{kWh}$} \\
\hline \multicolumn{3}{|c|}{ Initial Total energy loss } & \multicolumn{2}{|c|}{$4,658.3 \mathrm{kWh}$} \\
\hline \multicolumn{3}{|c|}{$\begin{array}{l}\text { E_SubSol\&Bat=E_LT- } \\
\text { E DG+E DGLoss }\end{array}$} & \multicolumn{2}{|c|}{$40,965.97 \mathrm{kWh}$} \\
\hline \multicolumn{3}{|c|}{$\begin{array}{l}\text { E_SubInitial=E_LT+Initial Total } \\
\text { energy loss }\end{array}$} & \multicolumn{2}{|c|}{$109,172 \mathrm{kWh}$} \\
\hline \multicolumn{5}{|c|}{$E_{\text {Substation }}(t)+E_{D G}(t)=E_{L T}(t)+E_{\text {Loss-Total }}(t)$} \\
\hline Case & E-SubSol\&Bat & E-DG & E-Load & E-Loss \\
\hline Initial & 109,172 & 0 & $104,513.7$ & $4,658.3$ \\
\hline B-SPVP & $40,965.97$ & $64,892.5$ & $104,513.7$ & $1,344.7$ \\
\hline
\end{tabular}

The lowest bus voltage has now improved to $0.983 \mathrm{pu}$ from $0.963 \mathrm{pu}$ that was there for optimized only with SPVP and from its original value of $0.899 \mathrm{pu}$ for the base case load flow. 
The self-sufficiency level of the Tissa 1 feeder for B-SPVP is $62.09 \%$. This means, with the installation of B-SPVP with a 6.598 MW SPVP together with a BESS of $14.663 \mathrm{MWh}$, the feeder is capable of catering $62.09 \%$ of its total energy requirement itself. Hourly variation of power from main grid, power from SPVP to charge the batteries and power from battery discharge with time, are depicted in Figure 7.

The hourly energy loss resulted from each three
To determine the SPP for the three cases, variable costs of each generating units that were in operation on $03^{\text {rd }}$ August 2018 [19] were taken into account together with their hourly generated energy. Hourly energy from each generator unit was then commensurate to match the total energy demanded from Tissa 1 feeder each hour. Since there is no variable cost of unit generated related to hydro power plants and SPVPs, variable costs of them were taken as zero.

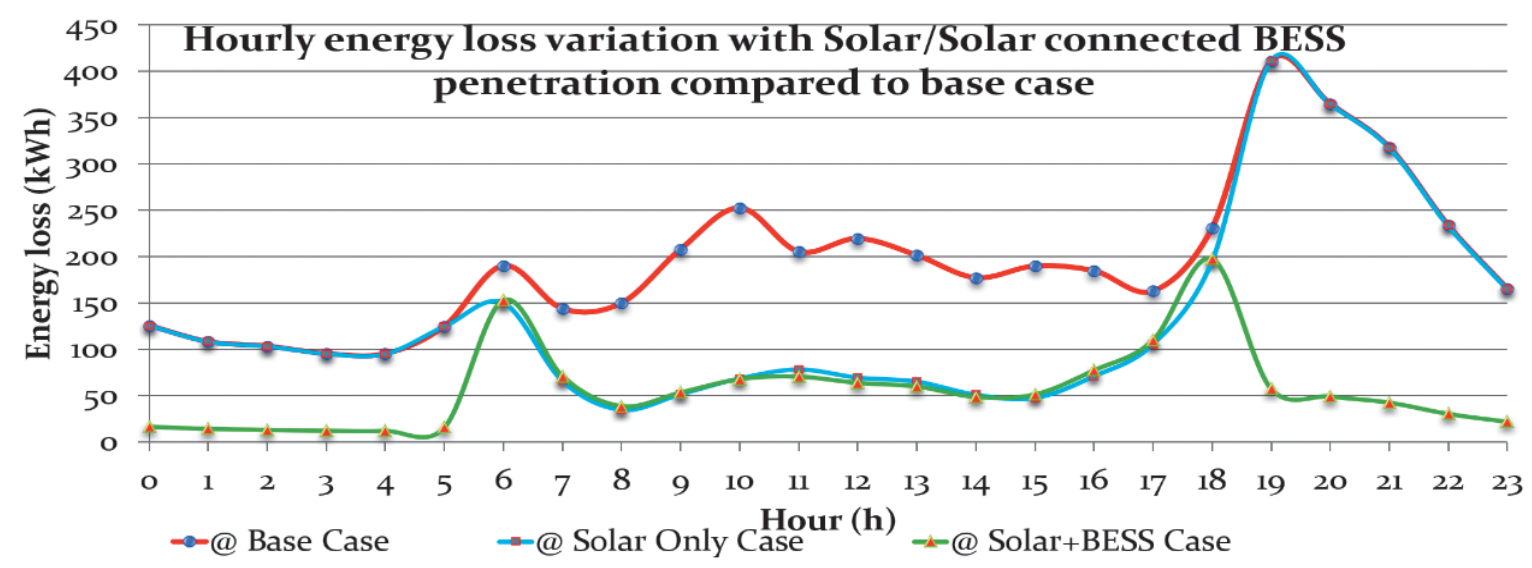

Figure 8 - Hourly Energy Loss Variation with Solar/Solar Connected BESS Penetration Compared to Base Case

cases considered are plotted against each hour in Figure 8. Since the SPVP and B-SPVP are connected in the proximity of network loads, i.e. at the Bus no. 149, reduced power losses have occurred when compared to the base case which draws all required energy from the main grid. During solar generation available times, loss variation curve of B-SPVP connected case follows the same curve of the SPVP loss variation.

When the minimum bus voltages in each bus are analysed for the three cases, the voltages have increased with the addition of SPVP which further escalated with the addition of BSPVP, within the acceptable voltage range. Thus the voltage constraint is preserved in both SPVP case and B-SPVP case in Tissa 1 feeder.

\section{Financial Evaluation Based on Optimized Results of Tissa 1 feeder}

For determination of financial viability of optimized SPVP and B-SPVP, a financial evaluation was carried out for three scenarios in terms of Simple Payback Period (SPP) and Levelized Cost of Energy (LCOE).The specific values used for the financial evaluation are tabulated in Table 5. Economic life of the plants is considered as 20 years with the costs incurred during construction, operation and maintenance during plant lives.
Table 5 - Specific Values used for Financial Evaluation

\begin{tabular}{|l|l|l|l|}
\hline \multicolumn{1}{|c|}{ Parameters } & \multicolumn{1}{c|}{$\begin{array}{c}\text { Case } \\
\text { A }\end{array}$} & $\begin{array}{c}\text { Case } \\
\text { B }\end{array}$ & \multicolumn{1}{c|}{$\begin{array}{c}\text { Case } \\
\text { C }\end{array}$} \\
\hline $\begin{array}{l}\text { Capital Cost for PV plant } \\
\text { (USD/kW) }\end{array}$ & 1,000 & 1,000 & 1,000 \\
\hline $\begin{array}{l}\text { Capital Cost for BESS } \\
\text { (USD/kWh) }\end{array}$ & - & 2,000 & - \\
\hline $\begin{array}{l}\text { Capital Cost for inverter } \\
\text { (USD/kW) }\end{array}$ & - & 270 & 270 \\
\hline Loan/Equity (\% / \%) & $70 / 30$ & $70 / 30$ & $70 / 30$ \\
\hline Project IRR (\%) & 10.71 & 10.14 & 10.87 \\
\hline
\end{tabular}

The three cases studied are: Case A: optimized SPVP is connected to the Tissa 1 feeder Case B: optimized B-SPVP is connected to the Tissa 1 feeder; and Case C: Determination of the Capital Cost of BESS (in USD/kWh) of B-SPVP to compete with small GT in Kelanitissa, at the optimum solution.

Unit cost of a BESS was found by keeping the LCOE of optimized B-SPVP to Rs. 45.00 subjected to the minimum of $10 \%$ IRR. This is because, in order to consider energy unit from B-SPVP to compete with power plants that are already in the Sri Lankan power system, the unit cost of energy generates from B-SPVP should be less than or equal to the highest unit cost power plant in the system, i.e. small Gas Turbine (GT) units in Kelanitissa power plant whose specific cost of generation unit is Rs. 45.00 on average. 
The SPP was also worked out for this case as well. Summary of the financial evaluation for the three cases are tabulated in Table 6.

Table 6 - Summary of Financial Evaluation for Optimized Tissa 1 Feeder SPVP and B-SPVP

\begin{tabular}{|l|l|l|l|}
\hline Parameters & Case A & Case B & Case C \\
\hline $\begin{array}{l}\text { Solar Plant Capacity } \\
(\mathrm{MW})\end{array}$ & 14.1 & 6.60 & 6.60 \\
\hline Total BESS size (MWh) & - & 14.7 & 14.7 \\
\hline $\begin{array}{l}\text { Capital Cost for PV plant } \\
\text { (USD/kW) }\end{array}$ & 1,000 & 1,000 & 1,000 \\
\hline $\begin{array}{l}\text { Capital Cost for BESS } \\
\text { (USD/kWh) }\end{array}$ & - & 2,000 & 135 \\
\hline $\begin{array}{l}\text { Capital Cost for inverter } \\
\text { (USD/kW) }\end{array}$ & - & 270 & 270 \\
\hline $\begin{array}{l}\text { Levelised Tariff } \\
\text { (LKR/kWh) }\end{array}$ & 22.00 & 175.00 & 45.00 \\
\hline Loan/Equity $\%$ / \%) & $70 / 30$ & $70 / 30$ & $70 / 30$ \\
\hline Project IRR (\%) & 10.71 & 10.14 & 10.87 \\
\hline $\begin{array}{l}\text { Simple Payback Period } \\
\text { (Years) }\end{array}$ & 16 & 156 & 26 \\
\hline NPV (USD mil) & 14 & 110 & 28 \\
\hline
\end{tabular}

When a SPVP of optimum capacity $14.06 \mathrm{MW}$ is connected to the bus no. 149 , in order to have a project IRR of $10 \%$, an energy unit generated from SPVP should be at least Rs. 22 per kWh and its NPV will be 14 USD million. Based on the energy benefit gain from SPVP, the capital cost can be recovered within 16 years. For the B-SPVP project IRR to be $10 \%$, in prevailing costs nowadays, an energy unit generated from B-SPVP is Rs. 175 per $\mathrm{kWh}$ which is why it is far too prohibitive to consider BESS units in the Least Cost Long Term Generation Expansion Plan (LCLTGEP) [12] in Sri Lanka. In order to be considering for base case of LCLTGEP, an energy unit generated from a B-SPVP should be Rs. 45 per $\mathrm{kWh}$ on average. If, one day, the capital cost of a BESS unit goes down to a value of USD 135 per kWh from today's value of USD 2,000 per $\mathrm{kWh}$, then Tissa 1 feeder can be made $62.09 \%$ self-sufficient in terms of energy while its NPV being 28 USD million. It is twice the NPV of a SPVP with optimum capacity which can make Tissa 1 feeder self-sufficient for $40.23 \%$ in terms of energy. Depending on the energy benefit gain from B-SPVP under Case C, the capital cost can be recovered within 26 years.

\section{Conclusions}

This paper presents a case study based optimal planning of SPVP and B-SPVP in distribution networks for total energy loss minimisation, subject to voltage and network power balance constraints.
In the study, generalized models have been developed for deciding the optimum size and place of SPVP and B-SPVP for minimum energy loss conditions. The optimizing function was assessed as the Total Energy Loss Index which is the ratio between the total energy losses when SPVP or B-SPVP to the total energy loss when neither SPVP nor B-SPVP is installed in the distribution network considered.

Further, a condition has been derived for optimum penetration levels for either SPVP or B-SPVP for minimum total energy losses and presented as Optimum Energy Levels expressed as a percentage of hourly total load.

A 33 kV Practical network in Sri Lanka, Tissa 1 feeder has been analysed to determine the optimum sizes for SPVP and B-SPVPas a percentage of Total connected load, respectively.

It is encapsulated that the addition of SPVP and B-SPVP can reduce power losses in the network while improving the voltage profile at the same time. Moreover, it has been found out that the losses can be further reduced and voltage profile can be further developed by co-locating BESS with SPVP as shown in Table 7.

Table 7 - Reduction in Total Power Losses \&Voltage Profile Improvement in Tissa 1 Feeder

\begin{tabular}{|l|l|l|l|}
\cline { 2 - 4 } \multicolumn{1}{c|}{} & $\begin{array}{l}\text { Base } \\
\text { case }\end{array}$ & $\begin{array}{l}\text { With SPVP } \\
\text { only }\end{array}$ & $\begin{array}{l}\text { With B- } \\
\text { SPVP }\end{array}$ \\
\hline $\begin{array}{l}\text { Voltage profile } \\
\text { improvement }\end{array}$ & $0.899 \mathrm{pu}$ & $0.963 \mathrm{pu}$ & $0.983 \mathrm{pu}$ \\
\hline $\begin{array}{l}\text { Total power loss } \\
\text { reduction (\%) }\end{array}$ & - & $31.4 \%$ & $71.13 \%$ \\
\hline
\end{tabular}

For a B-SPVP project of IRR being $10 \%$ in Sri Lanka, under prevailing costs, capital cost of BESS should fall to USD 135 per kWh from its current value of USD 2,000 per $\mathrm{kWh}$ to consider BESS units as a base case in the Least Cost Long Term Generation Expansion Plan in Sri Lanka. This would result in an energy unit generated from a B-SPVP to be Rs. 45 per $\mathrm{kWh}$ on average.

\section{References}

1. Nor, N. M., Ali, A., Ibrahim, T. and Romlie, M. F., "Battery Storage for the Utility-Scale Distributed Photovoltaic Generations", IEEE Access, Vol. 6, pp. 1137-1154, 2018.

2. Miller, T. and Edmonds, M. "Energy Storage can Enable Wider Deployment of Distributed Generation", 22nd International Conference and Exhibition on Electricity Distribution (CIRED 2013), Stockholm, 2013, pp. 1-4. 
3. Hung, D. Q., Mithulananthan, N. and Bansal, R. C., "Integration of PV and BES units in Commercial Distribution Systems Considering Energy Loss and Voltage Stability", Applied Energy, Volume 113, 2014, Pages 1162-1170, ISSN 03062619.

4. Georgilakis, P. S. and Hatziargyriou, N. D., "Optimal Distributed Generation Placement in Power Distribution Networks: Models, Methods, and Future Research", IEEE Transactions on Power Systems, Vol. 28, no. 3, pp. 3420-3428, Aug. 2013.

5. Tan, W. S., Hassan, M. Y., Majid, M. S. and Rahman, H. A., "Optimal Distributed Renewable Generation Planning:A Review of Different Approaches", Renewable and Sustainable Energy Reviews, Vol. 18, pp. 626-645, 2013.

6. Ru, Y., Kleissl, J. and Martinez, S., "Storage Size Determination for Grid-Connected Photovoltaic Systems," IEEE Transactions on Sustainable Energy, Vol. 4, no. 1, pp. 68-81, Jan. 2013.

7. Zhao, S., Zhao, X., Farnell, C., Mantooth, H. A., Umuhoza, J. and Zhang, Y., "A Daily Optimization Method for a PV-Battery Microgrid Considering the Battery Lifetime and Time-ofUse Pricing", IEEE Applied Power Electronics Conference and Exposition (APEC), Anaheim, CA, USA, 2019, pp. 3243-3250, 2019.

8. Sugihara, H., Yokoyama, K., Saeki, O., Tsuji, K. and Funaki, T., "Economic and Efficient Voltage Management Using Customer-Owned Energy Storage Systems in a Distribution Network With High Penetration of Photovoltaic Systems", IEEE Transactions on Power Systems, Vol. 28, no. 1, pp. 102-111, Feb. 2013.

9. Teng, J., Luan, S., Lee, D. and Huang, Y., "Optimal Charging/Discharging Scheduling of Battery Storage Systems for Distribution Systems Interconnected With Sizeable PV Generation Systems", IEEE Transactions on Power Systems, Vol. 28, no. 2, pp. 1425-1433, May 2013.

10. Teleke, S., Baran, M. E., Bhattacharya, S. and Huang, A. Q., "Rule-Based Control of Battery Energy Storage for Dispatching Intermittent Renewable Sources", IEEE Transactions on Sustainable Energy, Vol. 1, no. 3, pp. 117-124, Oct. 2010.

11. Acharya, N., Mahat, P. and Mithulananthan, N., "An Analytical Approach for DG Allocation in Primary Distribution Network" , International Journal of Electrical Power E Energy Systems, Vol. 28, Issue 10, 2006, Pages 669-678.

12. LONG TERM GENERATION EXPANSION PLAN 2018-2037, Ceylon Electricity Board.

13. Lazard's levelized cost of storage analysis Version 4.0.

14. 100\% ELECTRICITY GENERATION THROUGH RENEWABLE ENERGY BY 2050 Assessment of Sri Lanka's Power Sector, Also available online at: http:/ / www.adb.org\&http:/ / www.undp.org.
15. Hung, D. Q., Mithulananthan, N. and Lee, K. Y., "Determining PV Penetration for Distribution Systems with Time-Varying Load Models", IEEE Transactions on Power Systems, Vol. 29, pp. 30483057, 2014

16. Renné, D., George, R., Marion, B., Heimiller, D. and Gueymard, C., "Solar Resource Assessment for Sri Lanka and Maldives", National Renewable Energy Laboratory, Available online: http:/ / hienergyservices.com/assets/sri-lankasolar-resource.pdf August 2003 • NREL/TP-71034645.

17. Data sheet of JAP6 -72/305-325/4BB MULTICRYSTALLINE SILICON MODULE.

18. System control report on "Grid Substation Equivalent Load" on 2018/08/03, Ceylon Electricity Board.

19. System control report on "Log Data" on 2018/08/03, Ceylon Electricity Board. 